\title{
Epidemiological profile of female breast cancer in reproductive age-group and its association with maternal characteristics: -A population-based observational study in India
}

\author{
Perumal Vanamail ${ }^{\bowtie}$ \\ Perumal Vanamail, M.Sc., Ph.D., Department of Obstetrics and Gynaecology, All India Institute of Medical Science, New Delhi, India. \\ $\triangle$ Corresponding author: Dr. Perumal Vanamail <pvanamail@aiims.edu> \\ (C) The author(s). This is an open access article distributed under the terms of the Creative Commons Attribution License (https://creativecommons.org/licenses/by/4.0/). \\ See http:/ /ivyspring.com/terms for full terms and conditions.
}

Received: 2019.01.09; Accepted: 2019.03.24; Published: 2019.06.20

\begin{abstract}
Purpose: Even though the cancer incidence rate in India is lower than in developed countries, the mortality rate among cancer patients stood at 50\%. Further, India topped the list for mortality of breast and cervical cancers. In this scenario studying the epidemiological profile of women-based breast cancer among the reproductive age group (15-49 years) and determination of risk causes remains unknown.

Methods: Breast cancer data from 27 centres of the National Cancer Registry Programme in India during 2012-2014, provided the age-standardised incidence rate per 100,000 population and comparative incidence ratio (CIR) for different regions. Using all possible risk causes got from National Family Health Survey-4 report as covariates, Poisson regression model on cases provided incidence risk ratio (IRR) with 95\% confidence interval $(\mathrm{Cl})$.

Results: Around 8.33 (14.2\% of the population) crores females under surveillances formed into six regions based on the geographical location of each centre. Overall breast cancer incidence rate was 22.72 (Cl: 22.41-23.04) and varied between 10.46 in the North-eastern region and 33.86 in North region. About $40 \%$ of breast cancers formed in the reproductive age group and incidence rate was $16.5(\mathrm{Cl}$ : 16.116.8). For women using IUD or with blood sugar more than $160 \mathrm{mg} / \mathrm{dl}$, IRR was 1.06 (Cl: $1.04-1.08)$ and $1.19(\mathrm{Cl}: 1.11-1.28)$ respectively. Women with unmet need for spacing or with higher empowerment index were likely to be at lower risk. IRR for these two types of women was 0.97 ( $\mathrm{Cl}: 0.96-0.98)$ and 0.17 (Cl: 0.10-0.28) respectively.

Conclusion: Population-based observational study from India, which contributes about $18 \%$ of the total world population revealed that IUD usage and high blood sugar are significant risk factors. On the other hand, higher empowerment index emerged as a significant protective factor. Therefore, by approving the women for their health status and creating awareness using existing mobile-based social media such as WhatsApp, Facebook and Twitter on the importance of early detection followed by treatment, the chances of reducing maternal mortality associated with breast cancer will be possible.
\end{abstract}

Key words: Breast cancer, reproductive age group, observational studies, risk factors, -Comparative Incidence ratio, incidence risk ratio, India.

\section{Introduction}

Because of India's vast population size, the overall cancer incidence rate is steadily increasing and increase in women-specific breast cancer is rapid in an alarming situation [1,2]. Report [3] by Ernst and
Young (EY) Global limited in association with Federation of Indian Chamber of Commerce and Industry (FICCI) Ladies Organization shows the actual situation of cancer in India. In 2015, estimated 
cancer incidence cases were 1.0-1.4 million. Of this, breast cancer, cervix uteri and ovarian cancer shared $19 \%, 14 \%$ and $7 \%$ respectively and all these three types of cancer accounted for $40 \%$ of all cancer incidences among women. World Health Organization (WHO) developed a statistical report [4] called "GLOBOCAN" 2012 and showed that cancer afflicted more Indian women than men with the breast cancer in women ranks four in India compared to other countries. Reported data on all types of cancers increased from 0.45 million in 2005 to 0.7 million in 2015 showing an increased rate of $55 \%$. However, breast cancer among women was shown to be raised from 75,600 in 2005 to 1,34,200 in 2015 with an increased rate of about $78 \%$ [3]. The corresponding increased rate in China was $70 \%$ during the same period. Breast cancers have overtaken cervix uteri. According to the latest cancer registry of Indian Council of Medical Research (ICMR), breast cancer with an estimated 150,000 ( $>10 \%$ of all cancers) new cases during 2016 is the number one disease $[5,6]$.

Even though the cancer incidence rate ( 80 per 100,000 population) is far lower than developed countries such as Denmark and the US (300 per 100,000 population), only $30 \%$ of India's cancer patients survive over five years $[7,8]$. According to WHO's "GLOBOCAN" 2012 report [4] only one out of every five or six women newly diagnosed with breast cancer died in the USA, but the corresponding figure in India stood at 50\%. India also ranks among the top two countries globally on mortality for key women-specific cancers. Data shows cervical and breast cancer mortality rates in India are 1.6 to 1.7 times higher than the maternal mortality, highlighting the significantly adverse mortality rates for women-specific cancers in the country. India topped the list for the death of breast and cervical cancers and reported the second highest incidence of ovarian cancer globally.

Reproductive health is an essential part of general health and an innermost feature of human development. It is a worldwide concern for women during the reproductive age (15-49 years). Though most of the health-related complications arise during old age, general health status reflects earlier reproductive life events. Therefore, reproductive health is a pre-condition for social, economic and human development. Considering the importance of reproductive health, the present study focused on the epidemiological profile of women-based breast cancer among the reproductive age group. An earlier review work [9] done during the year 2017 had highlighted that in a large cohort study of women aged 15-44 years, the incidence of pregnancy-associated breast cancer (PABC) was 37.4 per 100, 000 live births during the study period (1963-2002).

Further, the incidence of breast cancer among pregnant women was said to be in the range of 1:10000 to 1:3000 [10]. In India, during the year 2015, the number of pregnancies was estimated to be 48.1 million [11]. Therefore, even if the minimum range $(1: 10,000)$ is valid in the present scenario, the co-existence of breast cancer patients during pregnancy is likely to be about 5000 in India. In a case series study [12] maternal mortality due to cancer was observed to be 1.23 per 100,000 population. In the light of these observations, the finding of the present study will have national implication on prevention and spread of advanced stage of cancer, and reducing maternal mortality because of breast cancer.

\section{Materials and Methods}

\section{Data source}

Study of interest was a population-based observational study. Indian Council of Medical Research (ICMR), the top body of scientific research in India, had started a network of cancer registries across the country under the National Cancer Registry Programme (NCRP) in December 1981. Now the NCRP programme involve in 27 [5] centres with the following main objectives.

Creating reliable data on the size and pattern of cancer; carrying out case-control or epidemiological studies on cancer disease; undertaking research activities that may be useful for developing a proper strategy for National Cancer Control and human well-being. Staffs involved in the programme make an effort to register all cancer patients, who are residents of that area at least for one year. Data collection sources are main cancer hospitals, general hospitals covering private and government. Further, Staff is visiting pathology laboratories involved in reporting of cancer patients to confirm the reported cases from available records such as patients' background characteristics and nature of cancer disease.

The centre-specific consolidated report published by NCRP during the period 2012-2014 formed the basis for the present study. Based on geographical location, we divided all the 27 centres into six regions and details are presented in Table 1. We hypothesised that possible maternal characteristics of the reproductive age group and background variables are also likely to be influencing causes of breast cancer. Therefore, at the district level in which the NCRP centreis located, we collected data from National Family Health Survey-4 (2015-2016) reports [13] as follows; Background variables such as 
literacy rate of females (\%); women with more than ten years of schooling (\%) and women's empowerment index; Maternal characteristics such as per cent of women married or pregnant in the age group 15-19 years; Women using the Intra-uterine device (IUD) or Postpartum IUD (\%); Women using pills (\%); Women with the unmet need for spacing (\%); Women with below average body mass index (\%); Women with overweight or obese (\%); Women with anaemic (\%); Per cent of women with high blood sugar level $(>140 \mathrm{mg} / \mathrm{dl})$; Per cent of women with high blood sugar level (>160 mg/dl); and Women underwent for breast examination (\%).

Table 1: Distribution of National Cancer Registry Centres by Regions

\begin{tabular}{ll}
\hline Region Name & Details of centres \\
\hline North-Eastern & Cachar, Dibrugarh-Annex, Kamrup-Urban, \\
& $\begin{array}{l}\text { Manipur-Annex, Meghalya, Mizoram, Nagaland, } \\
\text { Naharlagun, Pasighat, Sikkim, Tripura }\end{array}$ \\
North & Delhi, Patiala \\
East & Kolkatta-Annex \\
Central & Bhopal \\
West & Ahmedabad, Aurangabad, Barshi-expand, Barshi-rural, \\
& Mumbai-Annex, Nagpur, Pune, Wardha \\
South & Bengaluru, Chennai, Kollam-Annex, Trivendrum \\
\hline
\end{tabular}

\section{Statistical analysis used}

Using statistical software STATA version 12.0, we calculated age and gender-specific breast cancer incidence rate per 100, 000 populations with $95 \%$ confidence interval (CI) separately for each region. Since age-specific population distribution differed between regions, using direct age standardisation method we estimated age-standardised incidence rate and Comparative incidence ratio (CIR). For Poisson log-linear count model fitting, we considered centre wise breast cancer cases in the reproductive age group as a dependent variable; the corresponding population screened as offset variable $(\log 10$ population) and the list of possible maternal characteristics as covariates. The significance of regression coefficients, Akaike information criterion (AIC) and Bayesian information criterion (BIC) formed the basis for model fitting adequacy. The model that resulted in lesser values of AIC, BIC and significant coefficients emerged to be a satisfactory fit. We calculated the incidence risk ratio (IRR) with $95 \%$ $\mathrm{CI}$ and a probability value $\mathrm{P}<0.05$ was considered as statistical significance.

\section{Results}

In all the 27 centres, males' and females' population under surveillance was 8.82 and 8.33 crores respectively forming about $14 \%$ of the total population in India. Among males and females, crude cancer incidence rate $(95 \% \mathrm{CI})$ per 100,000 population was $0.72(0.66-0.77)$ and $24.6(24.3-24.9)$ respectively (Table 2). Male breast cancer forms about 3\% of total breast cancer cases in India. Presuming the age-specific female population of all the centres (8.33 crores) as the standard population, the data provided direct age-standardised incidence rate and CIR for each region (Table 3). Among the North region population, the CIR was more than threefold compared to the Northeast region, and in the remaining four regions CIR ranged between 2.1 and 2.8 times.

Of the total female population under surveillance, about $58 \%$ (4.8 crores) was in the reproductive age group. According to NFHS-4 survey [13], of 700,000 women surveyed in the age group, $15-49$ years currently married women was $73 \%$, and women with at least one parity status were $70 \%$. On account of this observation, among the cancer surveillance population of the reproductive age group the percentage of married women with at least one parity status was also likely to be more than $70 \%$ implying that the majority of the populations were with at least one parity status.

Table 2: Breast cancer incidence rate per 100,000 populations by region and gender

\begin{tabular}{|c|c|c|c|c|c|c|c|c|}
\hline \multirow{2}{*}{$\begin{array}{l}\text { Region Name } \\
\text { North East }\end{array}$} & \multirow{2}{*}{$\begin{array}{l}\text { Female population } \\
\text { covered }\end{array}$} & \multirow{2}{*}{$\begin{array}{l}\text { Incidence rate per } \\
100,000 \text { population } \\
9.66\end{array}$} & \multicolumn{2}{|c|}{$\begin{array}{l}95 \% \text { Confidence limits } \\
\text { Lower Upper }\end{array}$} & \multirow{2}{*}{$\begin{array}{l}\text { Male population } \\
\text { covered } \\
25648288\end{array}$} & \multirow{2}{*}{$\begin{array}{l}\text { Incidence rate per } \\
100,000 \text { population } \\
0.24\end{array}$} & \multicolumn{2}{|c|}{$\begin{array}{l}95 \% \text { Confidence limits } \\
\text { Lower Upper }\end{array}$} \\
\hline & & & 9.28 & 10.06 & & & 0.19 & 0.31 \\
\hline North & 10684885 & 34.53 & 33.44 & 35.67 & 12142608 & 1.31 & 1.12 & 1.53 \\
\hline East & 2149037 & 30.34 & 28.10 & 32.76 & 2338295 & 1.03 & 0.69 & 1.53 \\
\hline Central & 1931368 & 28.22 & 25.95 & 30.69 & 2088045 & 0.72 & 0.44 & 1.19 \\
\hline West & 25468717 & 24.54 & 23.94 & 25.16 & 28154246 & 0.82 & 0.72 & 0.93 \\
\hline South & 18364682 & 37.92 & 37.04 & 38.82 & 17824484 & 0.79 & 0.67 & 0.93 \\
\hline Overall & 83339076 & 24.59 & 24.25 & 24.93 & 88195966 & 0.72 & 0.66 & 0.77 \\
\hline
\end{tabular}


Table 3: Age-standardized female breast cancer incidence rate per 100,000 populations.

\begin{tabular}{lllll}
\hline $\begin{array}{l}\text { Region } \\
\text { Name }\end{array}$ & $\begin{array}{l}\text { Age standardized } \\
\text { incidence rate per } \\
100,000 \text { population }\end{array}$ & $\begin{array}{l}\text { 95\% Confidence } \\
\text { limits }\end{array}$ & $\begin{array}{l}\text { Comparative } \\
\text { Lowcidence ratio } \\
\text { (CIR) }\end{array}$ \\
\hline North East & 10.46 & 10.04 & 10.89 & 1.00 (Ref) \\
North & 33.86 & 32.77 & 34.96 & 3.2 \\
East & 22.75 & 20.99 & 24.50 & 2.2 \\
Central & 29.14 & 26.69 & 31.60 & 2.8 \\
West & 21.96 & 21.41 & 22.50 & 2.1 \\
South & 28.89 & 28.21 & 29.57 & 2.8 \\
Overall & 22.72 & 22.41 & 23.04 & \\
\hline
\end{tabular}

To find out probable causes that are likely to influence the event of cancer, we fitted a Poisson log-linear model to the cancer cases by taking all the possible maternal characteristics as covariates. Variables such as per cent of women opted for breast examination and school education level varied between the centres. Therefore, by adjusting these, the analysis provided a satisfactory fit, and the related statistics are presented in Table 5. The adequate model revealed the model coefficients for causes such as IUD usage, unmet need for spacing, overweight, very high blood sugar, marriage or pregnancy level in the younger age group 15-19 years and women empowerment index are statistically significant $(P=0.001)$. Of these factors, a substantial rise in the per cent of women with unmet need for spacing is likely to decrease cancer incidence by $3 \%$ with $95 \% \mathrm{CI}$ : $2 \%$ $4 \%$. Similarly, the increase in women empowerment index is a strong protective factor for cancer incidence. Presence of this factor alone is likely to lessen the incidence risk about $83 \%$, which ranges from $72 \%$ to 90\% (95\% CI).

The reproductive age group contributed nearly $40 \%$ of female breast cancer cases. Age-specific cancer incidence rate followed a J-type curve and fitting of power regression equation between age and incidence rate (Incidence rate $=6 \mathrm{e}-8^{*}$ Age $5.45 ; \mathrm{R} 2=0.993$ ) showed a satisfactory fit (Figure 1). Age-standardized incidence rate $(95 \% \mathrm{CI})$ was 16.5 (16.1 - 16.8). The trend in CIR remained similar to that of all the age-groups (Table 4).

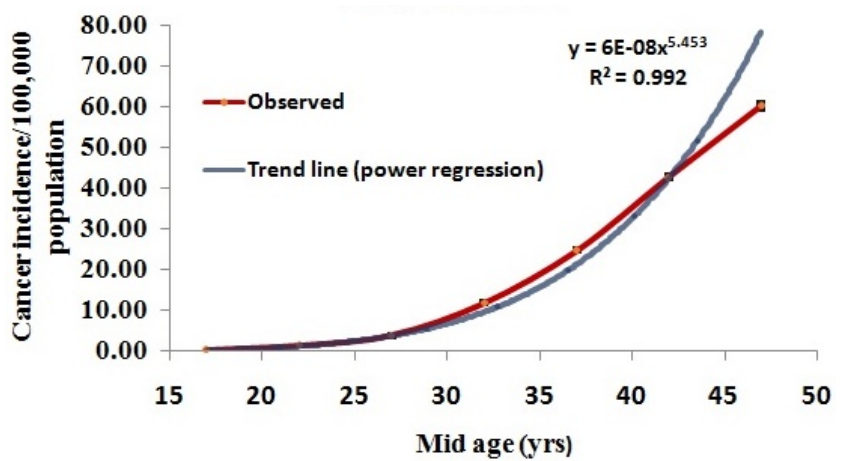

Figure 1. Age-specific female breast cancer incidence rate with $95 \%$ C.I

Table 4: Region wise female breast cancer incidence rate per 100,000 populations in the reproductive age group (15-49 years).

\begin{tabular}{|c|c|c|c|c|c|c|c|c|}
\hline \multirow{2}{*}{$\begin{array}{l}\text { Region Name } \\
\text { North East }\end{array}$} & \multirow{2}{*}{$\begin{array}{l}\text { Female population } \\
\text { covered }\end{array}$} & \multirow{2}{*}{$\begin{array}{l}\text { Crude incidence } \\
\text { rate per } 100,000 \\
\text { population }\end{array}$} & \multicolumn{2}{|c|}{$\begin{array}{l}\text { 95\% Confidence limits } \\
\text { Lower Upper }\end{array}$} & \multirow{2}{*}{$\begin{array}{l}\text { Age standardized } \\
\text { incidence rate per } \\
100,000 \text { population } \\
9.96\end{array}$} & \multicolumn{2}{|c|}{$\begin{array}{l}\text { 95\% Confidence limits } \\
\text { Lower Upper }\end{array}$} & \multirow{2}{*}{$\begin{array}{l}\text { Comparative incidence } \\
\text { ratio (CIR) } \\
1.00 \text { (Ref) }\end{array}$} \\
\hline & & & 9.07 & 10.1 & & 9.43 & 10.5 & \\
\hline North & 6273437 & 24.42 & 23.2 & 25.6 & 24.26 & 23.05 & 25.48 & 2.44 \\
\hline East & 1259582 & 20.01 & 17.54 & 22.48 & 17.33 & 15.19 & 19.48 & 1.74 \\
\hline Central & 1140044 & 21.4 & 18.72 & 24.09 & 22.06 & 19.29 & 24.83 & 2.21 \\
\hline West & 14832203 & 15.93 & 15.29 & 16.57 & 15.36 & 14.74 & 15.98 & 1.54 \\
\hline South & 10461807 & 23.71 & 22.77 & 24.64 & 20.32 & 19.52 & 21.12 & 2.04 \\
\hline Overall & 47969879 & 17.12 & 16.75 & 17.50 & 16.49 & 16.13 & 16.84 & \\
\hline
\end{tabular}

Table 5. Significant variables derived by Poisson regression model (adjusted for school education and breast cancer examination) for breast cancer incidence among reproductive age group.

\begin{tabular}{|c|c|c|c|c|c|}
\hline \multirow[t]{2}{*}{ Variables } & \multirow{2}{*}{$\begin{array}{l}\text { Incidence } \\
\text { Risk Ratio }\end{array}$} & \multirow[t]{2}{*}{ P-Value } & \multicolumn{2}{|c|}{ 95\% Confidence limits } & \multirow[t]{2}{*}{ Implication } \\
\hline & & & Lower & Upper & \\
\hline IUD use ( $\%$ women) & 1.06 & 0.001 & 1.04 & 1.08 & Likely to elevate breast cancer \\
\hline Unmet need spacing (\% women) & 0.97 & 0.001 & 0.96 & 0.98 & Likely to decrease breast cancer \\
\hline Overweight (\% women) & 0.99 & 0.001 & 0.98 & 0.99 & No solid evidence \\
\hline Women (\%) with blood sugar very high (>160 mg/dl) & 1.19 & 0.001 & 1.11 & 1.27 & Likely to elevate breast cancer \\
\hline Women $(\%)$ married or pregnant in $15-19$ years age group & 0.98 & 0.001 & 0.98 & 0.98 & No solid evidence \\
\hline Women empowerment Index & 0.17 & 0.001 & 0.10 & 0.28 & Likely to decrease breast cancer \\
\hline
\end{tabular}

Akaike's Information Criterion $(\mathrm{AIC})=336$; Bayesian Information Criterion $(\mathrm{BIC})=350$. 
Among the other significant factors, increase in IUD prevalence is likely to be a risk for cancer incidence and the expected excess risk with $95 \% \mathrm{CI}$ is $6 \%(4 \%-8 \%)$. Similarly, an increase in the prevalence of high blood sugar ( $>160 \mathrm{mg} / \mathrm{dl}$ ) level shows as the risk with 19\% excess risk (95\% CI: 11\%-27\%). Though the regression coefficients for overweight women and women either married or pregnant in the younger age 15-19 years are statistically significant, these two variables are not found to be clinically significant by witnessing 95\% CI, which are almost one for both lower and upper limits.

\section{Discussion}

To our knowledge, the present population-based study, particularly for reproductive age, may be the first in India, which contributes about $18 \%$ of the total world population. A similar study [14] carried out in the year 2017 was a review article based on limited data from seven cancer registry centres without the risk factor analysis. Therefore, the present study is comprehensive in the epidemiological point of view. India is a country of various cultures belonging to the various religion, castes and geographic regions. In light of these, studying region, specific breast cancer incidence will be useful to take the right policy decision. Region-specific observed incidence rate per 100,000 population varied widely between 9.7 (North-eastern) and 37.9 (South) with an overall incidence rate of 24.6. Age-standardised incidence rate (22.7) in the present study is close to an earlier estimate of 25.8 [14], and obviously, less than 92.9 observed among USA women in the same period [15]. Estimate of male breast cancer incidence rate $(0.72$ per 100,000 populations) in this study accounts for $3 \%$ of female breast cancer, while it is about $1 \%$ globally [16-18]. According to Indian census 2011 [19], the population size of transgender is approximately 0.5 million, and it is likely that a fraction of these individuals is male-to-female transsexual individuals. An earlier study [20] showed that five years of use of hormone replacement therapy (HRT) increased the risk of breast cancer by $10 \%$. Therefore, long-term use of HRT by transgender individuals might be an additional triggering cause for male breast cancer. Comparative incidence ratio for North region is three times more compared to the North-Eastern region. North region is mainly dominated by Delhi, capital of India and adaptation of western style in the form of food habit, lifestyle and family planning methods may be the causes for the higher cancer incidence. According to NFHS-4 [13] survey, the prevalence of alcohol consumption among females is $0.7 \%$, and any tobacco use is $1.8 \%$. Since these two causes are proven to be the risk of breast cancer [21-23], North region is showing higher CIR. In Central and South regions CIR is close to 3.0, while it is about 2.0 in East and West regions inferring the breast cancer incidence is influenced by variation in demographic characteristics, socio-cultural factors related to marriage and wish for having a child and lifestyle characteristics.

The crude breast cancer incidence rate among the reproductive age group was 17.1and it varied between 9.6 in the North-eastern region and 24.4 in the North region. The corresponding age-standard incidence rate was 16.5, 10.0 and 24.3 respectively. Incidence pattern in the reproductive age group is qualitatively similar and quantitatively different across regions. Since $40 \%$ of breast cancer cases were in the reproductive age group, the majority of these cases might be in the early stages (I \& II) and by effective management of these cases will increase the chance of survival. The remaining $60 \%$ of breast cancer cases might be either in pre-menopause or post-menopause period. As reported in "GLOBOCAN" 2012, in India more than 70\% of the cancers were in the advanced stages, early detection could go a long way in reducing the higher death rate compared to western countries. The higher death rate may also be confounding the effect of inadequate knowledge, fear and taboos.

Age-specific incidence rate fitted adequately to J-type growth model, and it provided a maximum incidence rate of 78 per 100,000 population for age at 47 years. This estimate corroborates with the age-specific incidence rate of Delhi obtained during 1988-2012 [14]. The Poisson regression model, which is suitable for rare event counts, revealed that for a unit increase in the per cent of women using IUD, the estimated risk is $6 \%$ more (95\% CI: $4 \%-8 \%$ ). An earlier study [24] conducted among Danish women showed a $20 \%$ higher risk among women who were currently using or had recently used contraceptives that use hormones, including birth control pills and intrauterine devices (IUDs). However, the importance of the increased risk is restricted to many factors such as age, weight, personal risk of breast cancer and lifestyle characteristics. A similar case-control study [25] also established the risk of using OCP for breast cancer. While a unit increase in the per cent of women with unmet need for spacing (those who wish to postpone their next birth by a specified length of time and who do not currently use a contraceptive method) risk ratio is likely to be decreased by $3 \%(95 \% \mathrm{CI}$ : $2 \%-4 \%)$. This finding indicates that delaying next childbirth without any contraceptive methods is a protective factor for breast cancer. The present study 
shows that increase in women with blood sugar more than $160 \mathrm{mg} / \mathrm{dl}$ is likely to elevate the breast cancer risk by $19 \%$ ( $95 \%$ CI: $11 \%-27 \%)$. The observation confirms an earlier study finding conducted in Italy based on the case-control study [26]. The authors inferred the breast cancer is directly associated with the consumption of sweet food, which increases insulin and insulin growth factors.

Interestingly this study also showed an excess risk of $19 \%$ (95\% CI: $2 \%-38 \%$ ). Therefore, it is evident that the consumption of more sweets that increase the insulin level is the risk cause of breast cancer and this evidence is established in an earlier study also [27]. Women empowerment is a creation of an environment for women, where they can make decisions of their own such as family size, family planning methods and their reproductive health condition. In the present study women empowerment index shows a significant protective factor for breast cancer and a unit increase in the index, breast cancer risk is likely to be decreased by $83 \%$ (95\% CI: $72 \%$ $90 \%$ ). Even though the other factors such as women with overweight or with sexual activity in 15-19 years of age were statistically significant, there was no clear evidence of clinical significance. A few studies on obesity or overweight [28-30] did not show any significant result on risk factor for breast cancer. A case-control study [31] revealed that certain factors such as marriage at an early age, use of OCP for more than three years and obesity were risk factors for breast cancer.

Given India's huge population size, it is impossible to scan each woman in the limited resource settings and therefore, the ultimate choice is self-examination and clinical examination involving public health ancillary professionals. While in the western countries, the culture is transparent openness and they are more aware due to interaction with their family members and friends. In India because of traditional cultural practice men don't discuss women's health and vice-versa. Further, it is believed to be a social stigma for revealing the symptom of breast cancer to others. An earlier study [32] had shown that with irrespective of socio-economic status and educational level, low level of awareness of breast cancer risk factors was reported.

Further, NFHS-4 survey reported that on average only $12.5 \%$ of women in the reproductive age group underwent for breast examination. Therefore, because of lack of awareness, there may be a negative attitude that unless something hurt or cause pain, the prior check-up is not required. Early detection is key to reduce mortality and chances of curing are more if it is detected at the initial stage. Further, Lack of a dedicated health care system is one of the main reasons for higher mortality.

According to the American Cancer Society estimate (Breast Cancer, Facts and Figures, 2017-2018) that a woman in the US has $12.4 \%$ or 1 -in- 8 , the lifetime risk of being diagnosed with breast cancer. However, breast cancer incidence in the United States during the period 2010-2014 was around 92 per 100,000 women. Expected increase in the lifetime risk over a period of five years was attributed to many factors such as longer life expectancy, frequent exposure for mammography and likelihood of increase in false positivity due to mammography, changes in reproductive pattern (early onset of menarche, delayed childbearing age and having fewer children), increase in obesity prevalence during post menopause and extensive use of postmenopausal hormone. In addition to these risk factors, lifestyle characteristics such as alcohol consumption and usage of birth control pills for a long duration are also observed to be possible risk factors. Anticipating these risk factors might inflate the breast cancer incidence in the US, integrated approaches like early detection of breast cancer through population-based mammographic screening and prompt treatment with surgery and radiotherapy were implemented. Further, systemic therapies that reduce the risk of metastatic spread has resulted in a significant reduction in breast cancer mortality. Furthermore, to mitigate cancer-related mortalities in high-income countries like the US and UK, there is a paradigm shift in health policy more from infectious diseases to non-communicable diseases with more resources allotment.

In low- and middle-income countries particularly in India, the scenario is different. India is a country of about 130 crores population with multi-linguistic and cultural systems. However, the joint family (living together and sharing food in the same dwelling) system is more prevalent in the country. Ultimately the authoritarian role in the family is associated with the eldest member in the family, and any decision-making power is concentrated in him/her. Due to these cultural barriers even for educated and working women the breast cancer subject is taboo and rarely discussed within the family. Therefore, common cultural barriers and unawareness of breast cancer together might be the limitations for abysmally poor coverage $(12.5 \%)$ of breast cancer examination in the reproductive age group.

Further, due to limited resources establishment of population-based mammographic scanning facility is not available at readily accessible points. This hiatus 
may also be one of the impeding factors for those who live in rural areas. To overcome these limitations men's understanding about breast cancer is pivotal and they should be a driving force to motivate women in their family for early detection and prompt treatment. Further, westernised lifestyles adoption is also growing fast in India and leads to more obesity. In the light of these observations following initiatives are likely to yield desired results.

India is progressing well in the field of communication network due to the active role of the private and public network system. According to the Telecom Authority of India [33], the total number of telephone subscribers as on April 30th 2017 was about 1,199 million, which was almost equal to the overall size of the population. Therefore, using the revolution of the communication system, creating awareness about preventable causes through mobile-based social media such as WhatsApp, Facebook and Twitter should be undertaken by government and civil society. Those who are at higher risk because of family history or ageing and lifestyle characteristics should be motivated for periodic screening in early detection and treatment to prevent mortality. Since detection and treatment cost of cancer in private hospitals involves enormous cost, hospitals run by the government should take the initiative to set up more cancer detection facilities and high standard of treatment. Further, with an act of government, mass screening of breast cancer by rural health nurses will be able to reduce the burden significantly among women. To compensate financial implication because of treatment cost, coverage of cancer insurance scheme may be immediate relief.

Limitation: An earlier study [34] observed that the patients with high parity or recent birth had worse breast cancer-specific survival compared with nulliparous or who gave birth more than ten years prior. Therefore, the significance of the parity status for breast cancer among the reproductive age-groups could not be established. Since the data provided by National cancer centres formed the basis for the present analysis, non-availability of breast cancer patients by parity status is a limiting factor. The second limitation is that the present study is not a cause-effect relationship study and it is a correlational study at the population level.

\section{Conclusion}

This study is unique in the sense it is a population-based epidemiological study covering about $14 \%$ of the total population from India, which contributes about $18 \%$ of the global population. Further, this study focused on the epidemiological profile of breast cancer in the reproductive age group and identified likely risk factors as well as protective factors for breast cancer. The probable risk/protective factors, which are not possible to establish through prospective study are the highlight of this study. About $40 \%$ of breast cancers formed in the reproductive age group and incidence rate was 16.5 (95\% CI:16.1- 16.8) per 100, 000 population. IUD usage or with high blood emerged as significant factors with IRR was 1.06 (CI: $1.04-1.08)$ and 1.19 (CI: 1.11-1.28) respectively. Women with unmet need for spacing or with higher empowerment index were observed to be protective factors with IRR was 0.97 (CI: $0.96-0.98$ ) and 0.17 (CI: $0.10-0.28)$ respectively. The study results implied that women should be adequately empowered to decide on their health aspects. Further, by utilising existing social media such as WhatsApp, Twitter and Facebook proper screening and awareness among the women can help them to undergo for the early diagnosis. Last but not least, we need to ensure the affordability of treatment as the cost of cancer treatment is significantly higher than that of other diseases.

\section{Acknowledgement}

The author acknowledged ICMR, India and NFHS-4 nodal agencies (International Institute of Population Sciences (IIPS), Mumbai, India and Ministry of Health and Family Welfare, India) for accessing data from their public domain.

\section{Ethics approval}

This study was carried out using the data from public domains (National Cancer Registry Programme and National Family Health Survey) of the Indian Government. Further, the article is submitted from India, and thus ethics approval was not required.

\section{Availability of data}

All data is available from public domains of NRCP and NFHS.

\section{Competing Interests}

The authors have declared that no competing interest exists.

\section{References}

[1] Breast_Cancer.pdf [Internet]. [cited 2018 Apr 8]. Available from: http://www.icmr.nic.in/guide/cancer/Breast_Cancer.pdf

[2] Green M, Raina V. Epidemiology, screening and diagnosis of breast cancer in the Asia-Pacific region: Current perspectives and important considerations. Asia-Pacific Journal of Clinical Oncology. 2008 Dec 1;4: S5-13.

[3] Call for action expanding cancer care in India 2017 - Google Search [Internet]. 2018 [cited 2018 Mar 22].

[4] GLOBOCAN 2012 - Home [Internet]. 2018 [cited 2018 Mar 28]. Available from: http://globocan.iarc.fr/. 
[5] Preliminary_Pages_Printed.pdf [Internet]. [cited 2018 Mar 27]. Available from: http://www.icmr.nic.in/ncrp/pbcr_2012-14/ALL_CONTENT/PDF_Printed _Version/Preliminary_Pages_Printed.pdf

[6] Sharma DC. Cancer data in India show new patterns. The Lancet Oncology. 2016 Jul 1;17(7):e272

[7] Allemani C, Weir HK, Carreira H, Harewood R, Spika D, Wang X-S, et al. Global surveillance of cancer survival 1995-2009: analysis of individual data for $25,676,887$ patients from 279 population-based registries in 67 countries (CONCORD-2). Lancet. 2015 Mar 14;385(9972):977-1010.

[8] Mallath MK, Taylor DG, Badwe RA, Rath GK, Shanta V, Pramesh CS, et al. The growing burden of cancer in India: epidemiology and social context. The Lancet Oncology. 2014 May;15(6):e205-12.

[9] Rossana R, Carmen H, Kathrin SW, Diego T, Jessica St. L, Alexandra B et al. Epidemiology and pathophysiology of pregnancy-associated breast cancer: A review. The Breast. 2017; 35: 136-141.

[10] Pavlidis NA. Coexistence of Pregnancy and Malignancy. The Oncologist. 2002; 7:279-287.

[11] Susheela S, Chander S, Rajib A, Ann MM, Melissa S, Manas RP et al. The incidence of abortion and unintended pregnancy in India, 2015. Lancet Glob Health.2018;6: e111-20

[12] de Haan J, Lok CAR, Shutte JS, Zuylen L, de Groot CJM. Cancer-related to maternal mortality and delay in diagnosis and treatment: a case series on 26 cases. BMC Pregnancy and Childbirth. 2018; 18:10:1-6.

[13] National Family Health Survey 2015-16 (NFHS-4) - state fact sheet.pdf [Internet]. [cited 2018 Feb 26]. Available from: http://rchiips.org/NFHS/factsheet_NFHS-4.shtml

[14] Malvia S, Bagadi SA, Dubey US, Saxena S. Epidemiology of breast cancer in Indian women: Breast cancer epidemiology. Asia-Pacific Journal of Clinical Oncology. 2017 Aug;13(4):289-95

[15] Liu F-C, Lin H-T, Kuo C-F, See L-C, Chiou M-J, Yu H-P. Epidemiology and survival outcome of breast cancer in a nationwide study. Oncotarget. $2017 \mathrm{Feb}$ 9;8(10):16939-50.

[16] Anderson WF, Jatoi I, Tse J, Rosenberg PS. Male breast cancer: a population-based comparison with female breast cancer. J Clin Oncol. $2010 \mathrm{Jan}$ 10;28(2):232-9.

[17] Male breast cancer: a population-based comparison with female breast cancer. - PubMed - NCBI [Internet]. 2018 [cited 2018 Feb 6]. Available from: https://www.ncbi.nlm.nih.gov/pubmed/19996029

[18] Male Breast Cancer (MBC) in Parma province: descriptive epidemiology, molecular markers and clinical variables [Internet]. ResearchGate. 2018 [cited 2018 Apr 9]. Available from: https:// www.researchgate.net/publication/295382815

[19] Census of India Website: Office of the Registrar General \& Census Commissioner, India [Internet]. [cited 2018 Mar 30]. Available from: http://censusindia.gov.in/2011-Common/CensusData2011.html
[20] Ross RK, Paganini-Hill A, Wan PC, Pike MC. Effect of Hormone Replacement Therapy on Breast Cancer Risk: Estrogen Versus Estrogen Plus Progestin. J Natl Cancer Inst. 2000 Feb 16;92(4):328-32.

[21] Mishra S, Joseph RA, Gupta PC, Pezzack B, Ram F, Sinha DN, et al. Trends in bidi and cigarette smoking in India from 1998 to 2015, by age, gender and education. BMJ Global Health. 2016 Apr;1(1):e000005.

[22] Vineis P, Wild CP. Global cancer patterns: causes and prevention. The Lancet. 2014 Feb;383(9916):549-57.

[23] Alberg AJ, Singh S, May JW, Helzlsouer KJ. Epidemiology, prevention, and early detection of breast cancer. Current Opinion in Oncology. 2000;12(6):515-20. - Google Search [Internet]. 2018 [cited 2018 Feb 5].

[24] Hunter DJ. Oral Contraceptives and the Small Increased Risk of Breast Cancer. New England Journal of Medicine. 2017 Dec 7;377(23):2276-7.

[25] Bethea TN, Rosenberg L, Hong C-C, Troester MA, Lunetta KL, Bandera EV, et al. A case-control analysis of oral contraceptive use and breast cancer subtypes in the African American Breast Cancer Epidemiology and Risk Consortium. Breast Cancer Res. 2015 Feb 21;17:22

[26] Tavani A, Giordano L, Gallus S, Talamini R, Franceschi S, Giacosa A, et al. Consumption of sweet foods and breast cancer risk in Italy. Ann Oncol. 2006 Feb 1;17(2):341-5.

[27] Pollán M. Epidemiology of breast cancer in young women. Breast Cancer Research and Treatment. 2010 Sep;123(S1):3-6.

[28] Renehan AG, Tyson M, Egger M, Heller RF, Zwahlen M. Body-mass index and incidence of cancer: a systematic review and meta-analysis of prospective observational studies. Lancet. 2008 Feb 16;371(9612):569-78.

[29] Munsell MF, Sprague BL, Berry DA, Chisholm G, Trentham-Dietz A. Body Mass Index and Breast Cancer Risk According to Postmenopausal Estrogen-Progestin Use and Hormone Receptor Status. Epidemiol Rev. 2014 Jan 1;36(1):114-36.

[30] Obesity and Cancer [Internet]. National Cancer Institute. 2018 [cited $2018 \mathrm{Feb}$ 21]. Available from: https://www.cancer.gov/about-cancer/causesprevention/risk/obesity/obesity-fact-sheet

[31] Yoo KY, Kang D, Park SK, Kim SU, Kim SU, Shin A, et al. Epidemiology of breast cancer in Korea: occurrence, high-risk groups, and prevention. J Korean Med Sci. 2002 Feb;17(1):1-6.

[32] Gupta A, Shridhar K, Dhillon PK. A review of breast cancer awareness among women in India: Cancer literate or awareness deficit? European Journal of Cancer. 2015 Sep;51(14):2058-66.

[33] Telecom Regulatory Authority of India, New Delhi. Press Release 13th June 2017, Number 43 (www.trai.gov.in)

[34] Xuezheng S, Hazel BN, Chiu-Kit Tse, Mary BB, Whitney RR, Mark ES et al. Association of ParityandTimesince Last Birth with Breast Cancer Prognosis by Intrinsic Subtype. Cancer Epidemiol Biomarkers Prev. 2016; 25(1): 60-67. 